\title{
Unusual Presentation of Gout: Intratendinous Tophus in the Patellar Tendon
}

\author{
Canan CİMŞİT, Onur BUĞDAYCI, Mustafa Erkin ARIBAL \\ Department of Radiology, Marmara University Pendik Training and Research Hospital, İstanbul, Turkey
}

Gout is a clinical disorder resulting from urate crystal deposition. ${ }^{1}$ Tendinopathy and enthesopathy are extra-articular gout manifestations. The common sites involved in knee are the popliteus tendon, cruciate ligaments, and quadriceps tendon. ${ }^{2}$ Although patellar tendon has been mentioned as a possible involvement site, to our knowledge, only three case reports exist in the literature, two of which were reported in triathletes mimicking patellar tendonitis precipitated due to prolonged exercises. ${ }^{3-5}$ In this article, we report a 34-year-old male patient with eight years history of gout who presented with one week history of pain and swelling of extremities. He underwent excision of the olecranon bursae and biopsy from the tophus involving first toe three years ago. Recurrent gouty attacks were treated with nonsteroidal anti-inflammatory drugs, colchicines (1 mg/day), and analgesics. Serum uric acid level was $11.9 \mathrm{mg} / \mathrm{dL}$, C-reactive protein was $18.2 \mathrm{mg} / \mathrm{dL}$. Allopurinol had been discontinued due to elevated liver enzymes (alanine transaminase: $132 \mathrm{U} / \mathrm{L}$; aspartate aminotransferase: $85 \mathrm{U} / \mathrm{L}$ ). Physical examination demonstrated tophi overlying the toe, and tenderness over the caudal aspect of patella. The patellar tendon was slightly thickened on radiographs. Soft tissue tophus at the interphalangeal joint causing adjacent erosive changes, and swelling of olecranon bursae were seen (Figure 1). Magnetic resonance imaging showed fusiform mass-like thickening of the proximal patellar tendon, measuring $30 \times 16 \mathrm{~mm}$, with intermediate signal on $\mathrm{T}_{1}$ weighted and $T_{2}$ weighted images. Edema of the tendon at insertion and patellar cortical irregularities not seen on radiograms were demonstrated (Figure 2).

The gold standard for diagnosis of gout is presence of monosodium urate crystals in tophi or aspirated fluid. ${ }^{1}$ Accurate classification of gout without crystal documentation is needed where synovial fluid aspiration cannot be performed. These issues led the international collaborative working group -American College of Rheumatology/European League Against Rheumatism- to develop new classification criteria. ${ }^{6}$ The entry criterion requires one episode of joint/ bursa swelling, pain, and tenderness. Presence of monosodium urate crystals is sufficient for diagnosis. The domains of this classification include clinical, laboratory, and imaging criteria like pattern of joint/bursa involvement, serum urate levels, radiographic gout related erosions, urate on dual-energy computed tomography (DECT), or double contour sign on ultrasound. Patient refused aspiration biopsy and DECT for the patellar lesion owing to his previous experiences and met the

Received: September 30, 2015 Accepted: October 01, 2015 Published online: November 02, 2015

Correspondence: Canan Cimşit, MD. Marmara Üniversitesi Pendik Eğitim ve Araştırma Hastanesi Radyoloji Anabilim Dalı, 34890 Üst Kaynarca, Pendik, İstanbul, Turkey. Tel: +90 532 - 5707387 e-mail: canancimsit@gmail.com

(02016 Turkish League Against Rheumatism. All rights reserved. 

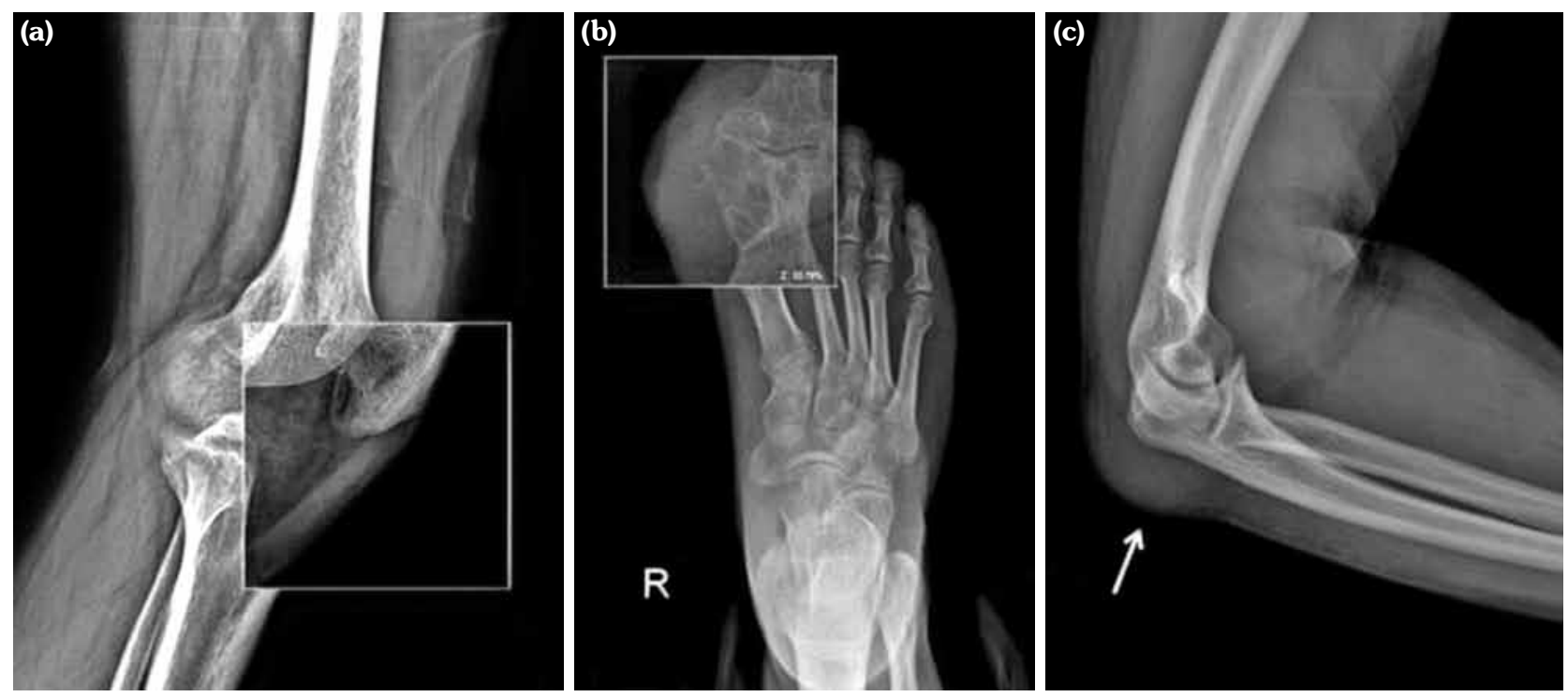

Figure 1. Radiographic findings of gout. (a) Lateral knee radiograph shows thickening of patellar tendon (magnified view in region of interest); (b) anteroposterior view of foot demonstrating soft tissue tophus at big toe and articular subchondral erosion at interphalangeal joint (magnified view in region of interest); (c) lateral radiograph of elbow demonstrating swelling of olecranon bursae (arrow).

American College of Rheumatology/European League Against Rheumatism gout classification criteria scoring 17/23.

Magnetic resonance imaging is highly sensitive in demonstrating extent and distribution of crystal deposits and differentiates tophi from benign and malignant neoplastic processes and infections. ${ }^{1,7,8}$
Computed tomography is very sensitive in identifying characteristic erosions and demonstrating the density of tophi as 170 Hounsfield units. $^{7}$ DECT shows uniquely color coded aggregates of urate crystals and differentiates gout from other arthritides like rheumatoid arthritis, pseudo-gout, and pigmented villonodular synovitis in the acute
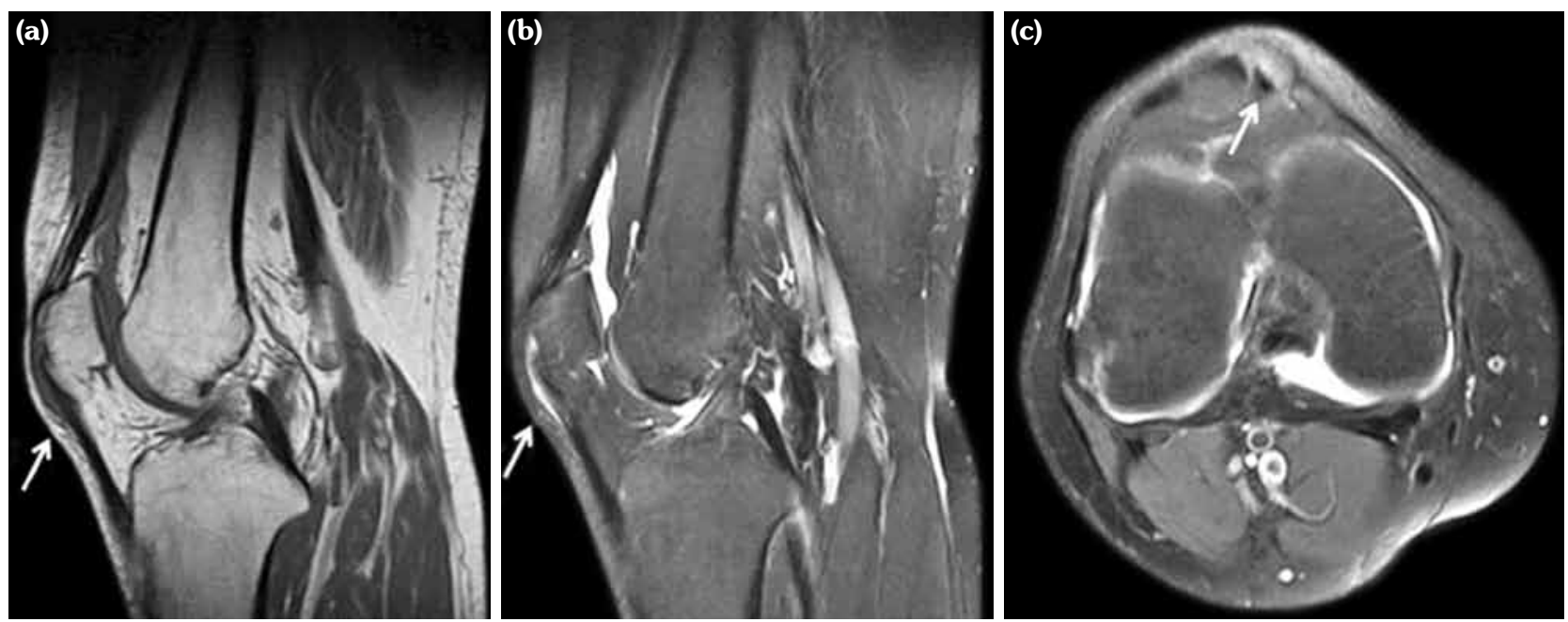

Figure 2. Magnetic resonance images demonstrating fusiform mass-like thickening of proximal patellar tendon at attachment site. (a) Sagittal $T_{1}$ weighted image show intermediate-to-low signal intensity and (b) $T_{2}$ weighted image intermediateto-high signal intensity tophaceous gout lesion involving entehesis site and proximal patellar tendon (arrow); (c) patellar cortical irregularity at enthesis site was also noted on axial fat saturated $\mathrm{T}_{2}$ weighted image (arrow). 
phase. , $, 6,8,9$ Monosodium urate crystals may preferentially deposit on hyaline cartilage giving "double contour sign" on ultrasound and this sign is suggested to be seen even before the development of erosive changes. A distinctly different pattern is present in pseudo-gout where crystal deposition is seen within the cartilage rather than the surface. ${ }^{7,10}$ Synovitis in gout tends to show concentric hyperechogenity unlike the frond-like synovial hypertrophy noted in rheumatoid arthritis. ${ }^{7}$

Diagnosing gout using imaging modalities varies in terms of demonstrating deposits as well as the extent and distribution of tophi in various stages of gout. The 2015 American College of Rheumatology/European League Against Rheumatism classification criteria represent an advance over previous guidelines, with improved performance characteristics and incorporation of newer imaging modalities, namely ultrasound and DECT. Our case shows the possibility of gout involvement of quite a rare site such as the patellar tendon and underlines the importance of early diagnosis with advanced imaging modalities to facilitate management of disease.

\section{Declaration of conflicting interests}

The authors declared no conflicts of interest with respect to the authorship and/or publication of this article.

\section{Funding}

The authors received no financial support for the research and/or authorship of this article.

\section{REFERENCES}

1. Ko KH, Hsu YC, Lee HS, Lee CH, Huang GS. Tophaceous gout of the knee: revisiting MRI patterns in 30 patients. J Clin Rheumatol 2010;16:209-14.

2. Mallinson PI, Reagan AC, Coupal T, Munk PL, Ouellette $\mathrm{H}$, Nicolaou $\mathrm{S}$. The distribution of urate deposition within the extremities in gout: a review of 148 dual-energy CT cases. Skeletal Radiol 2014;43:277-81.

3. Gerster JC, Landry M, Rappoport G, Rivier G, Duvoisin B, Schnyder P. Enthesopathy and tendinopathy in gout: computed tomographic assessment. Ann Rheum Dis $1996 ; 55: 921-3$.

4. Gililland JM, Webber NP, Jones KB, Randall RL, Aoki SK. Intratendinous tophaceous gout imitating patellar tendonitis in an athletic man. Orthopedics 2011;34:223.

5. Rodas G, Pedret C, Català J, Soler R, Orozco L, Cusi M. Intratendinous gouty tophus mimics patellar tendonitis in an athlete. $\mathrm{J}$ Clin Ultrasound 2013;41:178-82.

6. Neogi T, Jansen TL, Dalbeth N, Fransen J, Schumacher HR, Berendsen D, et al. 2015 Gout classification criteria: an American College of Rheumatology/ European League Against Rheumatism collaborative initiative. Ann Rheum Dis 2015;74:1789-98.

7. Girish G, Melville DM, Kaeley GS, Brandon CJ, Goyal JR, Jacobson JA, et al. Imaging appearances in gout. Arthritis 2013;2013:673401.

8. Askin A, Inci R, Akan O, Demirdal S, Bayram. A Rare cause of knee pain in gout patients: tophi of patella. Arch Rheumatol 2015;30:71-4.

9. Desai MA, Peterson JJ, Garner HW, Kransdorf MJ. Clinical utility of dual-energy CT for evaluation of tophaceous gout. Radiographics 2011;31:1365-75.

10. Thiele RG, Schlesinger N. Ultrasonography shows disappearance of monosodium urate crystal deposition on hyaline cartilage after sustained normouricemia is achieved. Rheumatol Int 2010;30:495-503. 